\title{
THE ORIGIN PRINCIPLE, TAX HARMONIZATION AND PUBLIC GOODS
}

\author{
by \\ Christos Kotsogiannis ${ }^{a}$, Miguel-Angel Lopez-Garcia ${ }^{b}$, and Gareth D. Myles ${ }^{c}$
}

This version: October 1, 2003

\begin{abstract}
This paper takes up two tasks. Firstly, it shows that the conclusion drawn in Lucas (2001) regarding potential Pareto improvement in small open economies needs to be amended: uniformity of taxes is required in addition to a condition on the initial deviation from optimality. Secondly, in large open economies, it verifies that some reasonable conjectures, concerning the welfare effects of a particular tax-harmonizing reform hold under the origin based tax system when public goods are present. It is shown that if both countries have the same marginal cost of public funds then the reform generates a potential Pareto improvement when global revenues are conditionally neutral. An actual Pareto improvement can be achieved under more stringent conditions: those of Nash equilibrium taxes and the Samuelson rule of public good provision.
\end{abstract}

Keywords: Origin principle; indirect tax harmonization; reform of commodity taxes; public goods

JEL classification: F15; H21; H41; H87.

Acknowledgements: Kotsogiannis acknowledges financial support from the Economic and Social Research Council (ESRC award L219252102). Lopez-Garcia acknowledges financial support from the Instituto de Estudios Fiscales and institutional support from the Spanish Science and Technology System (Project No. BEC2000-0415) and the Catalan Government Science Network (Project No. SGR2001-160). The usual caveat applies.

${ }^{a}$ Department of Economics, University of Exeter, School of Business and Economics, Streatham Court, Rennes Drive, EX4 4PU, England, UK. E-mail: c.kotsogiannis@exeter.ac.uk

${ }^{b}$ Departamento de Economia Aplicada, Universidad Autonoma de Barcelona, 08193 Bellaterna, Barcelona, Spain. E-mail: miguelangel.lopez@uab.es

${ }^{c}$ Department of Economics, University of Exeter, School of Business and Economics, Streatham Court, Rennes Drive, EX4 4PU, England, UK; E-mail: g.d.myles@exeter.ac.uk; Institute for Fiscal Studies. 


\section{Introduction}

As part of its objective to create an efficient common market, the European Union has long undertaken a legal and political commitment to establish a common system of commodity taxation based on the origin principle (commodities are taxed by-and revenues accrue to-the country that produces them). Central to the proposals of the European Commission was the movement of taxes towards a common average. Keen (1987) shows that a move of destination-based commodity taxes towards an appropriately weighted average would generate a potential Pareto improvement. An actual Pareto improvement is more difficult to establish (Keen (1989)). A limitation of Keen (1987, 1989 ) is that tax revenues are returned to consumers in a lump-sum fashion so there are no effects through public good expenditure. Delipalla (1997) introduces public goods and shows that, under certain conditions, indirect tax harmonization under the destination principle leads to a potential Pareto improvement. ${ }^{1}$

The parallelism between destination and origin taxation with public goods is not at all obvious, ${ }^{2}$ and consequently it is rather surprising that work on origin-based taxation is limited. Lopez-Garcia (1996), in a model without public goods, establishes that Keen's reforms are robust under origin taxation. Lucas (2001) considers public goods but he does so in a small open economy environment. Clearly this is a very restrictive environment, and arguably unrealistic for the issues at hand, since it ignores all interesting interactions through the international goods market. Also, his analysis contains a number of omissions. The objective of this paper is twofold: firstly, it amends the shortcomings in the analysis of Lucas (2001) and, secondly, it provides an answer to whether, in a large open economy, there is a welfare case for tax harmonization when government revenue finances a local public good and commodities are taxed under the origin principle.

\section{The model}

The basic framework is a standard general equilibrium model of international trade in which there are two countries labelled 'home' and 'foreign'. Home and foreign country variables are denoted by lower and upper case letters respectively. In each country there is a private sector (with a representative consumer) and a public sector. There are $N+1$ tradeable commodities. Each public sector produces a non-tradeable local public good

\footnotetext{
${ }^{1}$ See also Lahiri and Raimondos-Møller (1998) and Lopez-Garcia (1998).

${ }^{2}$ See, for instance, Keen and Smith (1996), Keen and Wildasin (2000), Kotsogiannis and Makris (2003) and Keen, Lahiri and Raimondos-Møller (2002) for a welfare comparison between the two principles of taxation.
} 
$g(G)$ financed by tax revenues and provided free of charge. Commodity taxation is origin based. Intergovernmental lump-sum transfers are permitted at some points. The implication of origin-based taxation is that in equilibrium the home-country consumerprice vector $q$ and the foreign-country consumer-price vector $Q$ will be the same but producer prices $p(P)$ may differ because of the presence of a commodity tax vector $t$ $(T)$.

Consumer preferences are represented by the expenditure function $e(q, u, g)(E(Q, U, G))$ with $e_{g}<0\left(E_{G}<0\right)$ representing the reduction in expenditure on the private goods as a result of an extra unit of consumption of the public good holding utility constant. The public sector is competitive and characterized by a restricted revenue function ${ }^{3}$ denoted by $r(p, g)(R(P, G))$ with $r_{g}<0\left(R_{G}<0\right)$.

Assuming it exists, an equilibrium for this economy is a set of values for the $N+5$ endogenous variables $\{q, U, u, g, G\}$ that satisfy market clearing and meet the budget constraints of the two consumers and two governments given the exogenous tax rates $\{t, T\}$. Conventional normalizations ${ }^{4}$ allows us to write the system that characterizes the equilibrium as

$$
\begin{aligned}
e_{q}(q, u, g)+E_{q}(q, U, G)-r_{p}(q-t, g)-R_{P}(q-T, G) & =0_{N}, \\
e(q, u, g)-t^{\prime} r_{p}(q-t, g)-z & =r(q-t, g), \\
E(q, U, G)-T^{\prime} R_{P}(q-T, G)+z & =R(q-T, G), \\
t^{\prime} r_{p}(q-t, g)+z & =-g r_{g}(q-t, g), \\
T^{\prime} R_{P}(q-T, G)-z & =-G R_{G}(q-T, G) .
\end{aligned}
$$

Equation (1) gives the market clearing conditions for the $N$ tradeable goods. Denoting by $z$ the level of transfers between the countries in units of the numeraire, equations (2) and (3) give the home and foreign budget constraints. The government budget constraints for the home and foreign country are given by (4) and (5).

We analyze harmonization by considering perturbations of this system. Throughout we assume that in each country income effects attach only to good 0 and so $e_{q u}=$ $E_{Q U}=0_{N \times 1}$. To remove two further inessential complications we suppose that public

\footnotetext{
${ }^{3}$ The restricted revenue function embeds all the usual properties of technology (Abe (1992)).

${ }^{4}$ We choose the first commodity, commodity 0 to be the numeraire and to be untaxed by both countries and so $t_{0}=T_{0}=0$ and $q_{0}=1=Q_{0}$. Walras' Law then allows us to drop the market-clearing equation for commodity 0 . The final system has $N+4$ equation in the same number of variables and is so exact.
} 
good provision does not affect: (i) the compensated demands for any good other than the numeraire (Wildasin (1979)) and so $e_{q g}=E_{q G}=0_{N \times 1}$, and (ii) supply for any other good other than the numeraire and so $r_{p g}=R_{P G}=0_{N \times 1}$.

\section{Small open economy}

We start the analysis by considering, as in Lucas (2001), a small open economy. The implication of this is that equation (1) is now redundant and so $d q=0_{N \times 1} \cdot{ }^{5}$

Perturbing equations (2) and (4), with $d q=0_{N \times 1}$, we obtain

$$
e_{u} d u=\left[\left(\frac{s_{g}}{r_{g}}\right) r_{p}^{\prime}-\frac{e_{g}}{r_{g}} t^{\prime} r_{p p}\right] d t+\frac{e_{g}}{r_{g}} d z
$$

where $e_{u}>0$ is the marginal utility of income and $s_{g} \equiv e_{g}-r_{g} \cdot{ }^{6}$ The optimal tax rate - defined by setting in (6) $d u / d t=0-$ is $t^{*}=\left(s_{g} / r_{g}\right) r_{p p}^{-1} r_{p}$. Substituting $t^{*}$ into (6) one obtains

$$
\frac{r_{g}}{e_{g}} e_{u} d u=\left(t^{*}-t\right)^{\prime} r_{p p} d t+d z
$$

Lucas (2001) considers reforms defined by $d t=\beta\left(t^{*}-t\right), d T=\beta\left(T^{*}-T\right)$, with $\beta>0$ and shows that they lead to an actual Pareto improvement in the sense that $d u, d U>0$ when $d z=0$. Though this is analytically correct it is entirely unconnected with the issue of harmonization. For in this case the reform is just uniform convergence towards the optimum taxes defined previously and so it is bound to raise welfare. ${ }^{7}$

We turn now to a reform that may generate a potential Pareto improvement that is, $d u>0, d U=0$ when $d z=0$. Setting $d U=0$ in the foreign counterpart of (6) gives $d z=\left(T^{*}-T\right)^{\prime} R_{p p} d T$. Substituting this into (7) one obtains

$$
\frac{r_{g}}{e_{g}} e_{u} d u=\left(t^{*}-t\right)^{\prime} r_{p p} d t+\left(T^{*}-T\right)^{\prime} R_{p p} d T .
$$

We now consider the tax reforms implying a non-uniform proportional convergence of

\footnotetext{
${ }^{5} \mathrm{~A}$ word of clarification is in order here. Though we do not find this a good assumption, for the simple reason that it removes all the interactions - hence much of the motivation for tax harmonizationbetween the two countries except that through the lump-sum transfers, we nevertheless pursue this case in order to correct the omissions in Lucas' (2001) analysis.

${ }^{6}$ The expressions for the foreign country, being similar, are omitted.

${ }^{7}$ To see this suppose that the tax vectors satisfy $t>t^{*}, T<T^{*}$ but $t<T$. Then this reform will reduce the home tax vector $t$, raise the foreign tax vector $T$, but move the two vectors further apart. This demonstrates that in this case, since there is no fiscal externality, the issue of harmonization is of no interest.
} 
domestic tax structures towards a target vector $H$ given $b^{8}$

$$
\left[\begin{array}{c}
d t \\
d T
\end{array}\right]=\beta\left[\begin{array}{c}
\psi(H-t) \\
\Psi(H-T)
\end{array}\right],
$$

where $\beta$ is a small positive scalar, $\psi, \Psi$ are arbitrary numbers and $H$-the common target $^{9}$ for the taxes - is an $N \times 1$ matrix given by

$$
H=\left(\psi r_{p p}+\Psi R_{P P}\right)^{-1}\left(\psi r_{p p} t+\Psi R_{P P} T\right)
$$

All reforms satisfying (9) have the property that

$$
r_{p p} d t+R_{P P} d T=0_{N}
$$

Substitution of (9) into (8) then gives

$$
\frac{r_{g}}{\beta e_{g}} e_{u} d u=\left[(t-T)-\left(t^{*}-T^{*}\right)\right]^{\prime} S(t-T)
$$

where

$$
S \equiv \Psi R_{p p}\left[\psi r_{p p}+\Psi R_{p p}\right]^{-1} \psi r_{p p}=\psi r_{p p}\left[\psi r_{p p}+\Psi R_{p p}\right]^{-1} \Psi R_{p p}
$$

is a positive definite matrix. ${ }^{10}$ Clearly the sign of (12) is ambiguous and thus additional restrictions must be imposed on the tax structure to obtain $d u>0$. Consider, for instance, the case in which both the initial and optimal tax rates are uniform, so that $t=\omega 1_{N}, t^{*}=\omega^{*} 1_{N}, T=\Omega 1_{N}$ and $t^{*}=\Omega^{*} 1_{N}$, where $\omega, \Omega$ are scalars. With these restrictions (12) becomes

$$
\frac{r_{g}}{\beta e_{g}} e_{u} d u=(\omega-\Omega)\left[\left(\omega-\omega^{*}\right)-\left(\Omega-\Omega^{*}\right)\right] 1_{N}^{\prime} S 1_{N}
$$

where, following from (13), $1_{N}^{\prime} S 1_{N}$ is positive. (14) points to an instance in which $d u>0$. Suppose that (without any loss of generality) $\Omega>\omega$ and so the foreign country has higher taxes initially. Suppose too that the divergence between actual and optimal tax rates is greater in the higher tax country at the initial position that is, $\left(\Omega-\Omega^{*}\right)>\left(\omega-\omega^{*}\right)$. Then we arrive at:

\footnotetext{
${ }^{8}$ The point here is established under a more general set of reforms (Lopez-Garcia (1998)). The tax coordinating reform in Lucas (2001) is the reform in Keen (1987) and Lopez-Garcia (1998) arrived at by setting $\psi, \Psi=1$ in (9).

${ }^{9} H=\Sigma t+\left(I_{N}-\Sigma\right) T$ is the common target for the taxes, where $\Sigma=\left(\psi r_{p p}+\Psi R_{P P}\right)^{-1} \psi r_{p p}$ and $I_{N}$ is the identity matrix of dimension $N$. It is clear that $H$ is a weighted average of the two initial tax structures, with the weights being dependent on local supply responses.
}

${ }^{10}$ See footnote 11 below. 
Proposition 1 With exogenous world consumer prices and uniform commodity taxes, the harmonizing reform (9)-(10) implies a potential Pareto improvement if the divergence between actual and optimal taxes is greater in the higher tax country than in the lower tax country.

It is clear then that, contrary to the claim in Lucas (2001), uniformity of taxes is required in addition to the condition on the initial deviation from optimality.

\section{Large open economy}

We now depart from Lucas (2001) by endogenizing the world commodity price vector $q$.

Perturbing equation (1) and solving for $d q$ we obtain

$$
d q=-\Lambda^{-1} r_{p p} d t-\Lambda^{-1} R_{P P} d T
$$

where $\Lambda \equiv e_{q q}+E_{q q}-r_{p p}-R_{P P}$ gives the derivative of the compensated world excess demands for the non-numeraire goods with respect to the non-numeraire prices. ${ }^{11}$ We assume that $\Lambda$ is negative definite (Dixit and Norman (1980)).

Perturbing equations (2) and (4), after substituting in (15), we obtain the welfare consequences of changes in the fiscal instruments for the home country

$e_{u} d u=\left[-\left(t^{\prime} r_{p p}-r_{p}^{\prime}\right) \gamma-r_{p}^{\prime}+\left(m^{\prime}-t^{\prime} r_{p p} \gamma\right) \Lambda^{-1} r_{p p}\right] d t+\left[\left(m^{\prime}-t^{\prime} r_{p p} \gamma\right) \Lambda^{-1} R_{P P}\right] d T+\gamma d z$,

where $m^{\prime}=e_{q}^{\prime}-r_{p}^{\prime}$ is the $N$-row-vector of imports of the non-numeraire goods for the home country and $\gamma \equiv e_{g} / r_{g}>0$. Notice that in equilibrium $e_{g} / r_{g}$ is equal to the Marginal Cost of Public Funds ( $M C P F)$ that is, the cost to the consumer of home country public good per unit of home country revenue. ${ }^{12}$

The welfare consequence of substituting the reform (9) into (16), following (11), is

$$
e_{u} d u=\left[-\left(t^{\prime} r_{p p}-r_{p}^{\prime}\right) \gamma-r_{p}^{\prime}\right] d t+\gamma d z
$$

Equation (17) is intuitive; the reform induces producer prices to change in such way that world consumer commodity prices remain constant at $q$. With constant $q$ the value

\footnotetext{
${ }^{11}$ Since $e_{q q}, E_{q q}$ are $N \times N$ negative semidefinite matrices and $r_{p p}, R_{P P}$ are $N \times N$ positive semidefinite matrices, $\Lambda$ is negative semidefinite.

${ }^{12}$ Whether, in equilibrium, public goods are over or under supplied depend on the divergence of the actual optimal rule from the Samuelson rule of optimal public good provision, $e_{g}=r_{g}$ (Atkinson and Stern (1974)).
} 
of imports also remain unaffected. Income changes due to the change in the producer price vector are also offset by the need to maintain some level of public good $g$. To put it differently, the loss in revenues due to the change in the producer price vector, $t^{\prime} r_{p p}$, is offset by the change in the public good supply. What is left, therefore, is the public good effect $-\left(t^{\prime} r_{p p}-r_{p}^{\prime}\right) \gamma d t$, the revenue effect $-r_{p}^{\prime} d t$, and the change in transfers $\gamma d z$.

To consider potential Pareto improvements set $d U=0$ in the foreign counterpart of (17). Solving for the level of transfer $d z$ and substituting this into (17), we obtain

$$
\begin{aligned}
M C P F_{h}^{-1} e_{u} d u= & -\left[\left(t^{\prime} r_{p p}-r_{p}^{\prime}\right) d t+\left(T^{\prime} R_{P P}-R_{P}^{\prime}\right) d T\right] \\
& -\left(M C P F_{h}^{-1} r_{p}^{\prime} d t+M C P F_{f}^{-1} R_{P}^{\prime} d T\right),
\end{aligned}
$$

where $M C P F_{h} \equiv e_{g} / r_{g}>0$ and $M C P F_{f} \equiv E_{g} / R_{g}>0$.

Equation (18) points to instances in which tax harmonization is potentially Pareto improving. Suppose for instance that $M C P F_{h}$ in the home country is equal to the foreign country's $M C P F_{f} \equiv \mu>0$ and that global tax revenues are conditionally neutral (so that the first bracketed term sums to zero). Conditional revenue neutrality implies that the change in world tax revenues at unchanged behavior, $r_{p}^{\prime} d t+R_{P}^{\prime} d T$, evaluated with the reform, is strictly negative and so on this score tax harmonization is potentially welfare improving. This is intuitive; conditional revenue neutrality implies that there is no revenue loss for the home country since there is one-to-one compensation from the country which gains to the country which loses from this reform. On this score the home country's welfare remains unchanged. A reduction in global revenues in turn implies that there are efficiency gains due to reduced production distortions (from a reduction in the producer price vector necessary to maintain fixed consumer prices). It is then easy to show that equation (18) simplifies to

$$
e_{u} d u=\beta(T-t)^{\prime} S(T-t)>0
$$

where the inequality sign follows from $\beta>0$ and the fact that $S$ is positive definite. Summarizing:

Proposition 2 Assuming that revenues are conditionally neutral and the MCPF in both countries equals $\mu>0$, then starting from an arbitrary tax-distorted equilibrium with $t \neq T$ the harmonizing reform (9)-(10) attains a potential Pareto improvement.

Proposition 2 generalizes the result in Lopez-Garcia (1996). In this particular instance, the existence of public goods does not affect the possibilities for an improving reform. 
We now investigate whether the reform is capable of achieving an actual Pareto improvement with $d u, d U>0$ and $d z=0$. Clearly, this imposes a more stringent requirement on the problem: for in this case there is one degree of freedom less due to the absence of the variable $z$, and so, in general, one should expect the achievement of an actual Pareto improvement to be highly dependent on the initial tax rates (Keen (1989)).

Setting $d z=0$ in (16) and its foreign counterpart, we obtain the welfare effects of a change in taxes

$$
e_{u} d u=\left[-\left(t^{\prime} r_{p p}-r_{p}^{\prime}\right) \gamma-r_{p}^{\prime}+\left(m^{\prime}-t^{\prime} r_{p p} \gamma\right) \Lambda^{-1} r_{p p}\right] d t+\left[\left(m^{\prime}-t^{\prime} r_{p p} \gamma\right) \Lambda^{-1} R_{P P}\right] d T \text {. }
$$

A natural step to follow in evaluating (20) is to assume that both countries follow the Samuelson rule of public good provision. Setting $e_{g}=r_{g}$ in (20) and using (9)-(10) one obtains

$$
e_{u} d u=-\beta t^{\prime} S(T-t)
$$

The sign of (21) is, in general, ambiguous: for, given that $S$-following from (13) - is positive definite, $t^{\prime} S t>0$ but $-t^{\prime} S T \gtrless 0$. An instance in which this ambiguity is removed is if countries behave as Nash competitors. In this case the Nash equilibrium level of taxes, denoted by $t_{n}^{*}$ for the home country and $T_{n}^{*}$ for the foreign are, respectively

$$
t_{n}^{*}=\left(r_{p p}+\Lambda\right)^{-1} m
$$

and

$$
T_{n}^{*}=\left(R_{P P}+\Lambda\right)^{-1} M
$$

It then follows that

$$
t_{n}^{* \prime} S T_{n}^{*}=-m^{\prime} \Phi m
$$

where $\Phi=\left(e_{q q}+E_{q q}-r_{p p}\right)^{-1} S\left(e_{q q}+E_{q q}-R_{P P}\right)^{-1}$ and so the sign depends on the matrix $\Phi=\phi[i, j]$. The definiteness of matrix $\Phi$ points to a situation in which the reform is capable of generating an actual Pareto improvement when starting from the Nash equilibrium. That would be, for instance, the case if there are no cross effects in consumption or production and so $\phi_{i j}=0 \forall i \neq j$. For in this case the product in (24) is unambiguously negative. Another possibility is to impose symmetry on matrix $\Phi$. Suppose that local supply responses are identical, at the initial position, in the sense that $r_{p p}=R_{P P}$. In this case $\Phi=\left(e_{q q}+E_{q q}-r_{p p}\right)^{-1} S\left(e_{q q}+E_{q q}-r_{p p}\right)^{-1}$ and so, being the product of two negative definite matrices, it is positive definite. ${ }^{13}$ Summarizing:

\footnotetext{
${ }^{13}$ These possibilities are also recognized in Lopez-Garcia (1996). The point here is established more generally with public good provision.
} 
Proposition 3 Suppose that international transfers do not exist, both countries follow the Samuelson rule, and either

(i) there are no cross effects in consumption and production, or

(ii) local supply responses are identical at the initial position.

Then indirect tax harmonization in the sense of (9)-(10), starting at the Nash equilibrium level of taxes, generates an actual Pareto improvement.

It is clear then that the tax harmonizing reform is capable of generating an actual Pareto improvement even if international compensatory transfers are unavailable though the sufficient conditions are stronger than with transfers.

\section{Conclusion}

This paper has taken up two tasks. Firstly, it showed that the conclusion drawn in Lucas (2001) regarding potential Pareto improvements in small open economies needs to be amended: potential Pareto improvements require uniformity and in addition a condition on the initial deviation from optimality. Secondly, in large open economies, it verified that some reasonable conjectures concerning the welfare effects of a particular tax harmonizing commodity reform - that of Keen (1987) and generalized in LopezGarcia (1998) - holds under the origin based tax system when public goods are present. In particular, it has been shown that if both countries have the same $M C P F$ then the reform generates a potential Pareto improvements when global revenues are conditional neutral. An actual Pareto improvement can be achieved under more stringent conditions: that of Nash equilibrium level of taxes and the Samuelson rule of public good provision. 


\section{References}

Abe, K, 1992, Tariff reform in a small open economy with public production, International Economic Review, 30, 209-222.

Atkinson, A. B., and N. Stern, 1974, Pigou, taxation and public goods, Review of Economic Studies, 41, 119-128.

Delipalla, S., 1997, Commodity tax harmonization and public goods, Journal of Public Economics, 63, 447-466.

Dixit, A. K., and V. Norman, 1980, Theory of International Trade. Cambridge: Cambridge University Press.

Keen, M. J., 1987, Welfare effects of commodity tax harmonization, Journal of Public Economics, 33, 107-114.

Keen, M. J., 1989, Pareto-improving indirect tax harmonization, European Economic Review, 33, 1-12.

Keen, M. J., S. Lahiri, and P. Raimondos-Møller, 2002, Tax principles and tax harmonization under imperfect competition: A cautionary example, European Economic Review, 46, 1559-1568.

Keen, M. J., and S. Smith, 1996, The future of value-added tax in the European Union, Economic Policy, 23, 373-411 and 419-420.

Keen, M. J., and D. Wildasin, 2000, Pareto efficiency in international taxation, American Economic Review, forthcoming.

Kotsogiannis, C., and M. Makris, 2003, Production efficiency in international taxation: A synthesis, Mimeo, University of Exeter.

Lahiri, S., and P. Raimondos-Møller, 1998, Public good provision and the welfare effects of indirect tax harmonisation, Journal of Public Economics, 67, 253-267.

Lopez-Garcia, M-A., 1996, The origin principle and the welfare gains from indirect tax harmonization, International Tax and Public Finance, 3, 83-93.

Lopez-Garcia, M-A., 1998, On welfare and revenue effects of indirect tax harmonization, Economics Letters, 60, 185-193.

Lucas, V., 2001, Tax harmonisation and the origin principle, Economic Letters, 71, 111-115.

Wildasin, D., 1979, Public good provision with optimal and non-optimal commodity taxation: The single-consumer case, Economics Letters, 4, 59-64. 


\section{THESE APPENDICES ARE FOR THE ATTENTION OF THE REFEREES ONLY AND NOT FOR PUBLICATION}

\section{Appendices}

\section{Appendix A}

\section{Derivation of equation (19) in text.}

We first show that conditional (on $d q=0_{N \times 1}$ ) neutrality means

$$
-\left[\left(t^{\prime} r_{p p}-r_{p}^{\prime}\right) d t+\left(T^{\prime} R_{P P}-R_{P}^{\prime}\right) d T\right]=0 .
$$

To see this denote global tax revenues by $\rho=t^{\prime} r_{p}(p, g)+T^{\prime} R_{P}(P, G)$. Upon perturbation, making use of the assumption in text that $r_{p g}=R_{P G}=0_{N \times 1}$, one obtains

$$
d \rho=t^{\prime} r_{p p} d p+r_{p}^{\prime} d t+T^{\prime} R_{P P} d P+R_{P}^{\prime} d T=0
$$

which, upon using $d p=d q-d t$, becomes

$$
d \rho=t^{\prime} r_{p p}(d q-d t)+r_{p}^{\prime} d t+T^{\prime} R_{P P}(d q-d T)+R_{P}^{\prime} d T=0 .
$$

Making now use of the consequence of the reform, that $d q=0_{N \times 1}$, (A.3) reduces to

$$
d \rho=-\left[\left(t^{\prime} r_{p p}-r_{p}^{\prime}\right) d t+\left(T^{\prime} R_{P P}-R_{P}^{\prime}\right) d T\right]=0
$$

Setting $M C P F_{h}=M C P F_{f}=\mu>0$ in (18) it remains now to show that $-\left(r_{p}^{\prime} d t+\right.$ $\left.R_{P}^{\prime} d T\right)>0$.

Solving (A.4) for $r_{p}^{\prime} d t+R_{P}^{\prime} d T,(18)$ becomes

$$
e_{u} d u=-\left(T^{\prime} R_{P P} d T+t^{\prime} r_{p p} d t\right) .
$$

Applying the reform to (A.5) then gives (19) in text that is,

$$
e_{u} d u=\beta(T-t)^{\prime} S(T-t)>0,
$$

where the inequality sign follows from the fact that $\beta>0$ and the matrix $S$ is positive definite.

\section{Appendix B}

Derivation of equations (22) and (23) in text.

If each country behaves as a Nash competitor choosing its origin-based commodity taxes to maximize the welfare of the representative citizen, taking the other country's taxes 
as given then these taxes are obtained, for the home country, by setting the coefficient of $d t$ in (20) equal to zero. Setting $e_{g}=r_{g}$ (and $E_{G}=R_{G}$ in the foreign counterpart of (20)) these taxes are then defined by

$$
t^{\prime}\left[r_{p p}+r_{p p} \Lambda^{-1} r_{p p}\right]-m^{\prime} \Lambda^{-1} r_{p p}=0_{1 \times N}
$$

for the home country, and

$$
T^{\prime}\left[R_{P P}+R_{P P} \Lambda^{-1} R_{P P}\right]-M^{\prime} \Lambda^{-1} R_{P P}=0_{1 \times N}
$$

for the foreign country.

Post-multiplying (B.1) by $\left[r_{p p}+r_{p p} \Lambda^{-1} r_{p p}\right]^{-1}$ and (B.2) by $\left[R_{P P}+R_{P P} \Lambda^{-1} R_{P P}\right]^{-1}$, simplifying and taking the transpose of the resulting equations one obtains (22) and (23) in the text. 